\title{
Receipt and Processing of RBOF/RRF Liquid Waste in H-Tank Farm (U)
}

by

J. E. Marra

Westinghouse Savannah River Company

Savannah River Site

Aiken, South Carolina 29808

This paper was prepared in connection with work done under the above contract number with the U.S. Department of Energy. By acceptance of this paper, the publisher and/or recipient acknowledges the U.S. Government's right to retain a nonexclusive, royalty-free license in and to any copyright covering this paper, along with the right to reproduce and to authorize others to reproduce all or part of the copyrighted paper. 


\section{DISCLAIMER}

This report was prepared as an account of work sponsored by an agency of the United States Government. Neither the United States Government nor any agency thereof, nor any of their employees, makes any warranty, express or implied, or assumes any legal liability or responsibility for the accuracy, completeness, or usefulness of any information, apparatus, product, or process disclosed, or represents that its use would not infringe privately owned rights. Reference herein to any specific commercial product, process, or service by trade name, trademark, manufacturer, or otherwise does not necessarily constitute or imply its endorsement, recommendation, or favoring by the United States Government or any agency thereof. The views and opinions of authors expressed herein do not necessarily state or reflect those of the United States Government or any agency thereof.

This report has been reproduced directly from the best available copy.

Available to DOE and DOE contractors from the Office of Scientific and Technical Information, P.O. Box 62, Oak Ridge, TN 37831; prices available from (615) 576-8401.

Available to the public from the National Technical Information Service, U.S. Department of Commerce, 5285 Port Royal Road, Springfield, VA 22161. 


\section{DISCLAIMER}

Portions of this document may be illegible in electronic image products. Images are produced from the best available original document. 


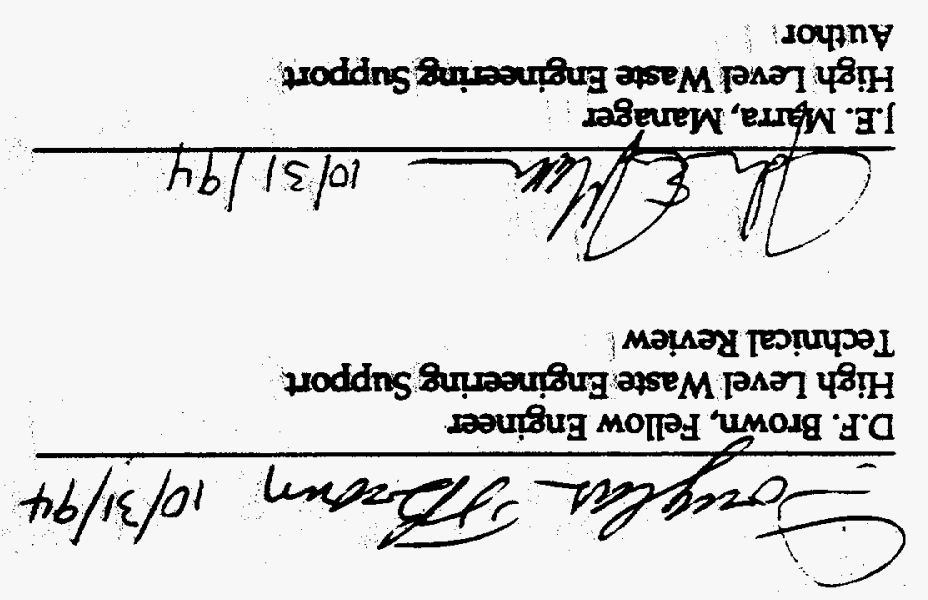

\section{(n) WAVI YNVI-H NI AISFM GIOOTI Iक्षय/OAY 10 ONISSAOOYd CNV IdIEDAY}

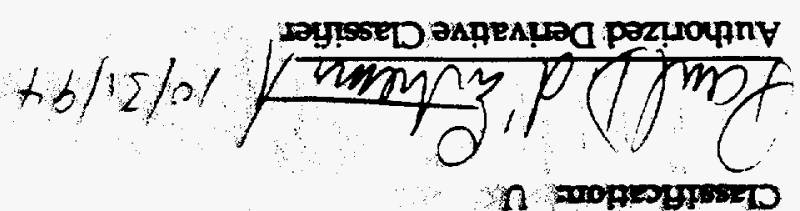

prevernad mopard

vop̣ezumu!̣,

anseM JPR/JO8Y

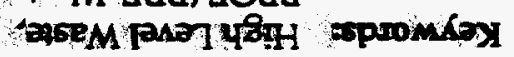

(ד6/0L) 0 'Aәy 0ZS0-\$6-YII-JYSM

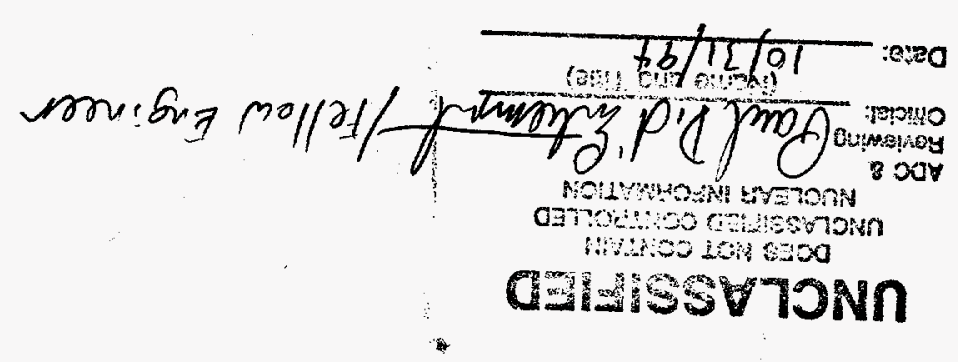


WSRC-TR-94-0520

Rev. 0 (10/94)

Page 2 of 11

October 31, 1994

\section{INTRODUCTION AND SUMMARY}

The Receiving Basin for Off-Site Fuels/Resin Regeneration Facility (RBOF/RRF) currently generates approximately 50,000 gallons of wastewater per month. This waste is sent to the 211-H General Purpose (GP) evaporator and/or the 241-H Tank Farm (HTF). The primary criteria for selecting the destination of the waste are solids content and radioactivity. The waste is typically sent to the GP evaporator if it has low solids content and low activity. High activity and/or high-solids content waste is sent to HTF (Tank 21H or Tank 23H depending on activity level). Currently, approximately $70 \%$ of the waste water produced at RBOF/RRF meets the criteria for acceptance by the GP evaporator.

In June 1993, High Level Waste Engineering (HLWE) opened a Technical Issue (HLE-TI-93-024) related to processing of RBOF/RRF directly through the $1 \mathrm{H}$ Cesium Removal Column (CRC) to the F/ H Effluent Treatment Facility (ETF). This issue was raised due to uncertainties associated with operation of the $1 \mathrm{H}$ Evaporator. In March 1994, additional emphasis was placed on this effort after it was determined that the $1 \mathrm{H}$ evaporator had a failed tube bundle. As a result, HLE-TI-93-024 was expanded to include evaluations of methods to increase the acceptance rate of RBOF/ RRF wastewater at the GP (i.e., to ensure that the $70 \%$. of RBOF/RRF wastewater that currently meets the GP acceptance criteria is actually processed at the GP).

Since March 1994, significant progress has been made to increase the operating efficiency of the GP evaporator for processing RBOF/RRF wastewater. This operating efficiency increase is due to increased coordination between RBOF/RRF and GP evaporator personnel and efforts to increase the staging capacity for storing RBOF/RRF wastewater at 211-H. Since March 1994, waste receipts from RBOF/RRF have averaged less than the 30,000 gallons/month allotted in the HLW System Plan. In addition, the RBOF/RRF waste sent to HTF has successfully been processed through the $2 \mathrm{H}$ evaporator. Based on this progress, no additional effort should be expended to reduce the amount of $R B O F / R R F$ sent to HTF, either by increasing the criteria for acceptance of RBOF/RRF waste at the GP evaporator or by evaluating alternate treatment options (such as processing through the 1H CRC or installing treatment equipment in the RBOF/RRF).

\section{DISCUSSION}

\section{RBOE/RRF Wasie Smeama}

Handling of wastewater produced at the RBOF/RRF Facility is controlled by procedure. 1 Specifically, this procedure addresses the RBOF/RRF waste streams 
WSRC-TR-94-0520

Rev. 0 (10/94)

Page 3 of 11

October 31, 1994

shown in Table I. Table I also lists the potential destination(s) for these waste streams as specified in procedure 244-H-1011.

Table I

RBOF/RRF Waste Streams and Destiriation

RBOF/RRE Waste Type

Filter Backflush (FB)

Harp Flush (HF)

Caustic Flush (CF)

Oxalic Acid Flush (OF)

Transfer Solution (TS)

Resin Classification (RC)

Resin Regeneration (RR)

Deionizer Rinses (DR)

Final Rinse (FR)

Cask Wash Pit Solution (CWP)

Cell Sump (CS)

Rainwater (MS)
Destination

Tank 21H (21) or Tank 23H (23)

21 or 23

23.

23

GP Evaporator (GP), 21, or 23 .

GP, 21 , or 23

GP, 21 , or 23

GP, 21 , or 23

GP, 21 , or 23

GP, 21 , or 23

GP, 21 , or 23

GP, 21 , or 23

The final destination of waste that can be received either at the GP Evaporator, Tank $21 \mathrm{H}$, or Tank $23 \mathrm{H}$ is determined largely by activity level and the availability of the GP evaporator to process the wastewater. Approximately $70 \%$ of the wastewater currently generated by the RBOF/RRF meets the criteria for acceptance at the GP evaporator.

The four types of RBOF/RRF waste (FB, HF, CF, OF) that can only be sent to the HTF are restricted from the GP evaporator due to high solids content. Although neither the RBOF/RRF Waste Handling procedure ${ }^{1}$ or the $211-\mathrm{H}$ waste receipt procedure $^{2}$ specify a maximum value on solids content of waste sent to the GP evaporator, previous operating history has shown that processing these four types of waste at the GP results in operational problems. Determination of the final destination in HTF (i.e., Tank 21 or 23 ) is determined largely by activity level. All waste sent to Tank 21 or Tank 23 must meet the HLW Liquid Waste Acceptance Criteria. ${ }^{3}$

A schematic diagram of the process flow for RBOF/RRF wastewater is shown in Figure 1.

\section{Open Techizical berue HIEE-TH-93-024.}

In June 1993, Figh Level Waste Engineering (HLWE) opened a Technical Issue (HLE-TI-93-024) related to processing of RBOF/RRF directly through the 1H Cesium Removal Cohumn (CRO) to the F/H Effluent Treatment Facility (ETF). 
WSRC-TR-94-0520

Rev. 0 (10/94)

Page 4 of 11

October 31, 1994

This issue was opened due to concerns with the operation of the $1 \mathrm{H}$ Evaporator and followed-up on a previously drafted Test Authorization (TA) to operate the $1 \mathrm{H} \mathrm{CRC}$ with a recently developed resorcinol-formaldebyde resin in the spring of 1994 concerns were raised about the ability of the tank farms to produce the space available in Type III tanks $(3,000,000$ gallons) necessary to support the start-up of the Defense Waste Processing Facility (DWPF). These concerns were increased when it was discovered that the $1 \mathrm{H}$ Evaporator had a failed tube bundle. As a result, HLE-TI-93-024 was broadened to generally address the need to reduce the impact of RBOF-RRF waste transfer on Type III waste tank available space to zero. Three activities were identified to minimize the impact of RBOF/RRF waste transfers on Type III tank available space

1. Maximize the Efficienicy of the GP Evaporator for Processing RBOF/RRF Waste,

2. Evaluate Options for Processing RBOF/RRF Waste Directly Though the $1 \mathrm{H}$ CRC to ETF (the original intent of HLE-TI-93-024), and

3. Evaluate Alternate Processing Options for RBOF/RRF Waste Effluent. Each of these activities is briefly described below.

\section{Maximize the Efficiency of the GP Evaporator for Processing RBOF/RRF Waste}

Several actions were identified to increase the acceptance rate for RBOF/RRF waste at the GP Evaporator.4.5 Each of these activities is described briefly below. A Performance Indicator has been developed to track RBOF/RRF Waste transfers to the tank farm (Figure 2).

1.1. Increase Coordination Between RBOF/RRF \& 211-H Outside Facilities.

The primary goal of this activity is to drive the RBOF waste acceptance rate at the GP to $100 \%$. That is, all of the RBOF/RRF waste that meets the GP Evaporator acceptance criteria is actually processed at the GP. As seen in the Performance Indicator (Figure 2), since the original meetings between HLW, RBOF, and GP personnel in March 1994, the acceptance rate at the GP has increased significantly. Steam problems and resultant backlog of GP feed are responsible for the low rate of septance in July. Other factors (i.e. - lack of adequate staging area, cher feed streams, etc) will continue to limit the acceptance rate of RBOF waste at the GP and are being addressed separately. Haweve: aver the last several monthi, the RBOF/RRF waste transfers. to HTF have been below the 30,000 gallons/month currently forecast in the HLW System Plan 6 
WSRC-TR-94-0520

Rev. 0 (10/94)

Page 5 of 11

October 31, 1994

\subsection{Increase Staging Area @ 211-H}

Efforts are currently underway to convert Tank 716 at $211-\mathrm{H}$ to a staging vessel for RBOF waste. Several problems were identified during walkdowns of the initial design that have delayed work on this task. These problems have been corrected and work to implement this design is in progress. This work will continue Scheduled modifications to Tank 716 are scheduled to be complete by 3/31/95.

\section{Remove Restrictions on 211-H Bottomsi Transfers}

Another factor which limits the ability of the GP to process RBOF waste is the ability to transfer the bottoms from the GP to H-Tank Farm. These restrictions are primarily due to construction activities at HDB-7. Since the initial meetings in March 1994, coordination between GP and HTF personnel has improved significantly and restrictions on GP bottoms transfers are no longer a limiting factor on processing RBOF waste at the GP.

The Performance Indicator on RBOF/RRF waste transfers is updated monthly by HLWE. A 75\% acceptance rate by the GP evaporator has been established as the goal for RBOF/RRF waste. Should the acceptance rate drop below $75 \%$ (without obvious reason, i.e., shutdown of the GP evaporator) or the volume of RBOF/RRF waste exceed the HIW System Plan ${ }^{6}$ forecast for consecutive months, a new Technical Issue will be opened. As specified by the HLW Waste Acceptance Criteria, ${ }^{3}$ quarterly Waste Generator Coordination Meetings will be held with RBOF/RRF and Separations personnel.

2 Evaluate Options for Processing RBOF/RRF Waste Directly Though the 1H CRC to ETF

As discussed previously, the original intent of Open Technical Issue HLE-TI-93024 was related to processing the RBOF/RRF waste that is sent to Tank 23H through the $1 \mathrm{H}$ Cesium Removal Column (CRC). This option bypasses the evaporator and, therefore, does not impact space available in Type III waste tanks. In this option, the RBOF/RRF waste is mixed with the $1 \mathrm{H}$ overheads and then processed through the $1 \mathrm{H} C R C$. The CRC typically operates with a "charge" of zeolite. Previously, when the RBOF/RRF stream was processed through the CRC, performance of the CRC was less than adequate. The column reached a high dP after processing a small number of bed volumes. It was postulated thiat the hight dP was due either tor degradation of the zealite on plugging of the CRC with solids entrained in the stream. Zeolite degradation was believed to the primary factor contributing to the poor CRC performance, however, a formal evaluation of the zeolite degradation was nat performed. It was suggested that 
WSRC-TR-94-0520

Rev. 0 (10/94)

Page 6 of 11

October 31, 1994

the high $\mathrm{pH}$ of the RBOF/RRF waste stream ( 14) contributed to the zeolite degradation. Zeolite is known to degrade at high $\mathrm{pH}$.

About that same time, the resorcinol-formaldehyde resin was becoming available It was suggested to replace the zeolite "charge" with the new resin. This was viewed as a way around the zeolite degradation issue and may have allowed processing directly to the CRC (without blending with $1 \mathrm{H}$ overheads).

A Test Authorization was prepared for this option, but was never approved. The primary problem with the use of the resorcinol-formaldehyde resin in the CRC is that the only (reasonable) way to remove the resin from the CRC is to open up the drain valve and allow it to drain to the waste tank. Adding this amount of organic to the tankigoes beyond current practice and requires careful consideration:

Since the last time RBOF waste was processed through the CRC, the procedures have been modified so that RBOF now neutralizes only to $\mathrm{pH} 10-12$. West. Valley Nuclear Services (WVNS) current operates a zeolite column at low $\mathrm{pH}$ $(-12)$ and low temperature $\left(-10^{\circ} \mathrm{C}\right)$ and obtains excellent bed-life. Although the $1 \mathrm{H}$ CRC operates at near-ambient temperatures $\left(20-30^{\circ} \mathrm{C}\right)$, it was determined the reduction in $\mathrm{pH}$ may reduce the amount of zeolite degradation. Based on this, it was recommended that a field trial be conducted to evaluate the performance of the zeolite and the ability of the CRC to "direct process" RBOF/RRF waste to the ETF. Several efforts were undertaken to return the $1 H$ $\mathrm{CRC}$ to service. Progress on this field trial was delayed by priorities associated with the $2 \mathrm{H}$ evaporator restart and difficulties in pressure testing the CRClines due to leaky valves.

However, even if the field tests showed that the CRC performed acceptably, it is still necessary to "dump" the zeolite to the waste tank when the column performance degrades. Although several tanks currently contain large quantities of zeolite, removal and processing this material through the DWPF is currently an Open Technical Issue. 7 In addition, as discussed above, much of the RBOF/RRF waste contained in Tank $23 \mathrm{H}$ has successfully been processed through the $2 \mathrm{H}$ evaporator. Based on the successful performance of the $2 \mathrm{H}$ evaporator, and the reduction in RBOF/RRF waste sent to HTF, the field test to evaluate the performance of the zeolite CRC is not warranted at this time. It is recommended that efforts to return the 1H CRC to service (solely for processing RBOF/RRF waste) be deferred.

\section{Evaluate Alternate Processing Options for RBOF/RRF Waste Effluent.}

A number of altemative processing options ior the RBOP/RRR waste eflivent were also considered and are brietly described belaw. 
WSRC-TR-94-0520

Rev. 0 (10/94)

Page 7 of 11

October 31, 1994

\subsection{Evaluate GP Evaporator Acceptance Criteria}

As discussed previously, the primary factor that limits acceptance of RBOF/RRF waste at the GP Evaporator is solids content. However, none of the procedures ${ }^{2-3,8-9}$ related to the transfer and receipt of RBOF/RRF waste make specific reference to the solids content of the waste, nor is the solid content measured prior to transfer. As shown in Table I, the RBOF/RRF waste transfer procedure does specify which types of waste produced at RBOF/RRF can be transferred to the GP: Evaporator. These wastes are primarily restricted from the GP due to the fact that they are generated from operations that produce solids in the liquid effluent. In the past, processing these types of wastes at the GP has resulted in operational problems. In order to process additional RBOF/RRF waste at the GP Evaporator, the maximum solids content of waste sent to the GP Evaporator would have to be quantitatively defined. In addition, the solids content of the RBOF/RRF would have to be determined before sending the waste to: the GP Evaporator.

\section{2. "Direct" Processing RBOF/RRF Waste at the F/FIETF}

Some of the waste produced by RBOF/RRF could be processed at the ETF. Although the activity limits for transfer of waste to ETF ( $<5,000$. $\mathrm{d} / \mathrm{m} / \mathrm{ml})$ are far less than those for the GP Evaporator $(<400,000$ $\mathrm{d} / \mathrm{m} / \mathrm{ml}$ ), it may be possible to process a significant portion of the RBOF/RRF waste at the ETF if the ETF acceptance criteria ${ }^{10}$ can be relaxed or if the RBOF waste can be mixed with other lower activity waste at the ETF. In order to accomplish this, a detailed evaluation of the ETF acceptance criteria and characterization of the RBOF/RRF waste streams for chemical inventory, radionuclides, etc would need to be performed. In addition, transfer capability directly from RBOF/RRF to the ETF does not currently exist. Further, since the ETF is a South Carolina Department of Health and Environmental Control (SCDHEC) permitted facility, revision of the ETF permit may be required before RBOF/RRF waste could be processed at the ETF.

\subsection{Installation of Waste Processing Capability at RBOF}

As part of the Office of Technology Development (OTD) activities funded by DOE EM-50, several Compact Processing Units (CPUs) are being developed which could be installed at RBOF/RRF to process wastewaten int the RBDF/RRP fadity The CPUscuresatly being developed include skid-mounted ion exchange and evaporator urits. These units could be used to reduce the activity and volume of the RBOF/RRF stream prion to transfer. These CPUs are currently in the 
WSRC-TR-94-0520

Rev. 0 (10/94)

Page 8 of 11

October 31, 1994

design and testing stage and, as such, are not available for production use. As the CPUs continue to be developed, their use at RBOF/RRF should continue to be evaluated.

Further development of any of these options would require a significant investment of manpower and potential equipment and design changes. Again; based on the successful performance of the $2 \mathrm{H}$ evaporator, and the reduction in RBOF/RRF waste sent to HTF, additional effort to implement any of these alternative processing options is not warranted at this time.

\section{CONCUUSIONS}

Significant progress has been made to increase the operating efficiency of the GP Evaporator for processing RBOF/RRF wastewater. This operating efficiency increase is due to increased coordination between RBOF/RRF and GP evaporator personnel and efforts to increase the staging capacity for storing RBOF/RRF wastewater at 211-H. Since March 1994, waste receipts from RBOF/RRF have averaged less than the 30,000 gallons/month allotted in the HLW System Plan. In addition, the RBOF/RRF waste sent to HTF has successfully been processed through the $2 \mathrm{H}$ evaporator. Based on this progress, it is recommended that additional effort to reduce the amount of RBOF/RRF sent to HTF, either by increasing the criteria for acceptance of RBOF/RRF waste at the GP evaporator or evaluating alternate treatment options (such as processing through the $1 \mathrm{H}$ CRC or installing treatment equipment in the RBOF/RRF) be deferred.

\section{REFERENCES}

1. Procedure 244-H-1011, "Waste Handling (U)," Rev. 19, July 7, 1994

2 Procedure 211-H-1025, "Building 211-H Waste Transfers (U)," Rev. 14, July 7,1994 .

3. G.K Georgeton, "Criteria for Acceptance of High level Liquid Waste into the 241-F/H Tank Farms (U)," X-SD-G-00001, Rev. 0, April 22, 1994.

4. G. T. Wright to J. G. McKibbin, "Increasing Operating Efficiency of 211-H General Purpose Evaporator For Processing RBOF Waste (U)" HLW-HLE-94-0404, March 29, 1994

5. I. G. McKibbin ta G. T. Wright, Methods Eviduation / horeasing Operating Efficiency of 211-H General Purpose Evaporator For Processing RBOF: Waste (U) " NMP-SFM-94005a May 16, 1994 
WSRC-TR-94-0520

Rev. 0 (10/94)

Page 9 of 11

October 31, 1994

6. N.R. Davis, "HLW System Plan - Revision 3 (U)," HLW-OVP-94-007, May 31, 1994.

7. Open Technical Issue WRE-019, "Equipment and Heel Removal."

8. Procediure 241-1H-601, "Receiving Liquid Waste from RBOFRRF (U), Rev. 14, January 15, 1994.

9. Procedure 241-1H-601A, "Liquid Waste from RBOF-RRF Worksheet (U)," Rev. 4, January 14, 1994.

10. WastelAcceptance Criteria for the F/Af Effuest Treaturent Facility (ETE) ane Currently in Development. 
WSRC-TR-94-0520

Rev. 0 (10/94)

Page 10 of 11

October 31, 1994

Figure 1

Schematic Diagram of RBOF/RRF Waste Processing Flow

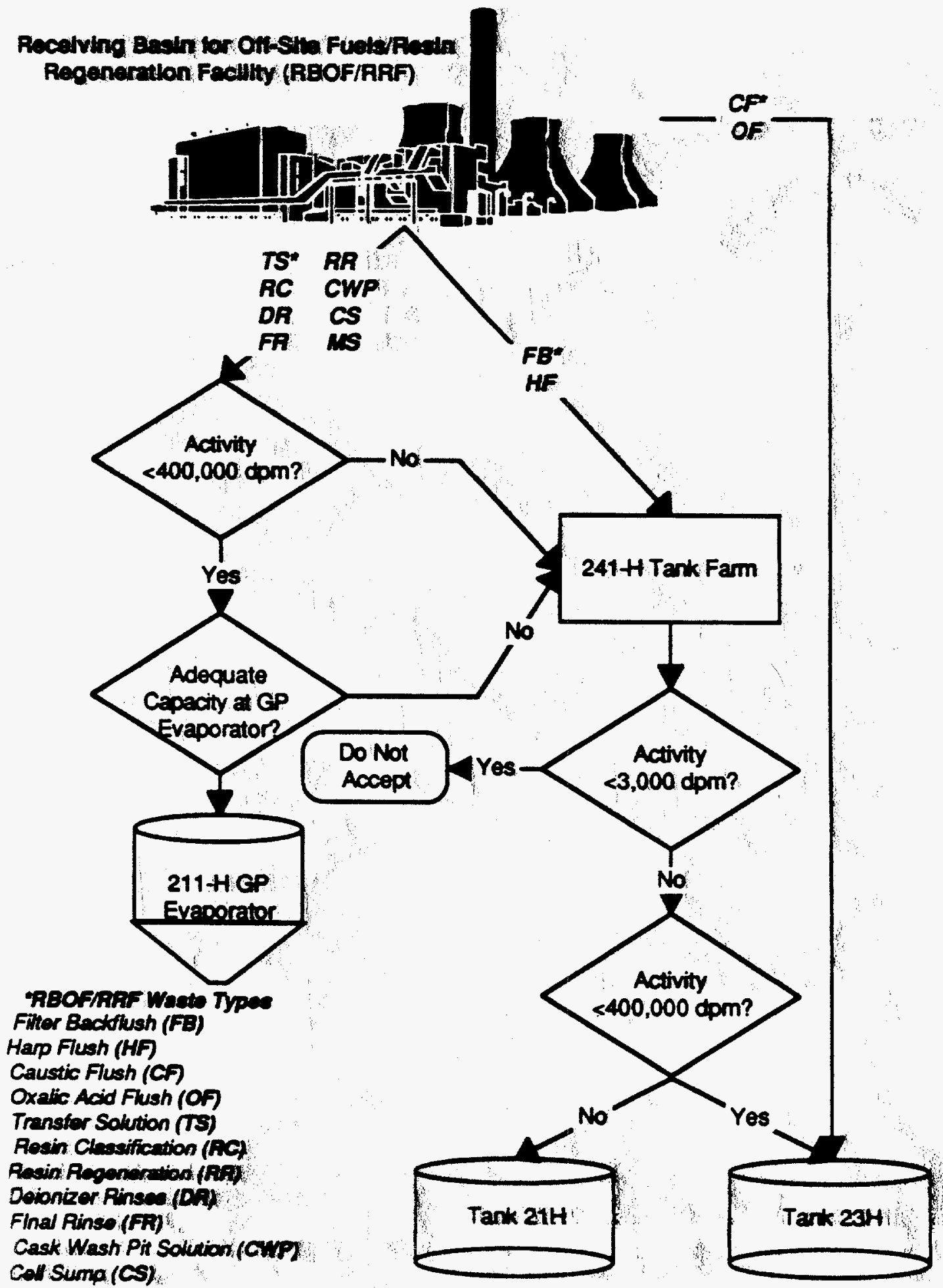

Cantar 
WSRC-TR-94-0520

Rev. 0 (10/94)

Page 11 of 11

October 31, 1994

Figure 2

Performance Indicator - RBOF/RRF Waste Transfers to H-Tank Farm

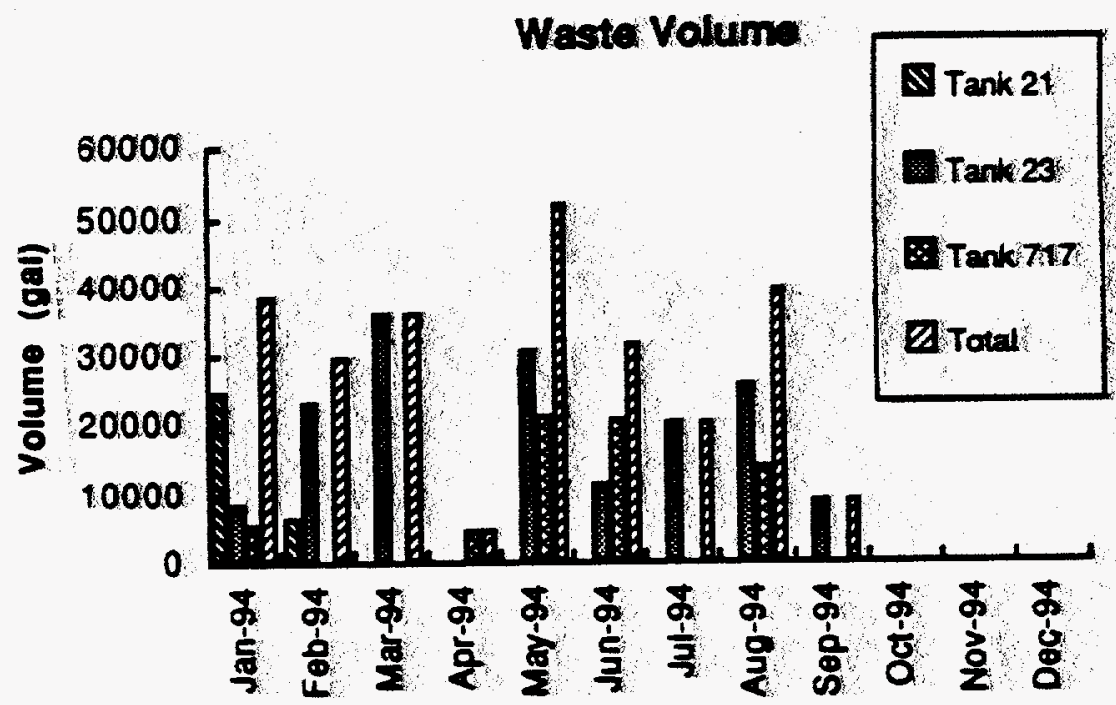

2a-Volume Transferred - Calendar Year 1994 To-Date

Outside Facllities Acceptance

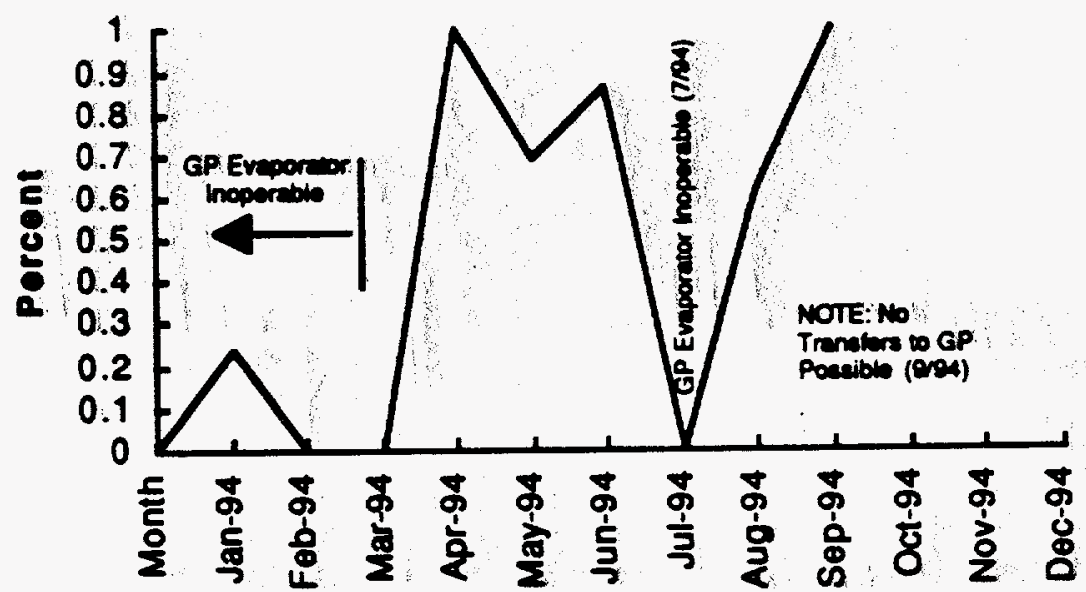

2b-Acceptiance Rate at 211-HT GP Evapouaton (Hy) Volumel 


\title{
RECEIPT AND PROCESSING OF RBOF/RRF LIQUID WASTE IN H-TANK EARM (U)
}

\author{
G.T. Wright, 703-H \\ T.J. Lex, $7194 \mathrm{~A}$ \\ J.W. French, 703-H \\ E.R. Losure, 707-H \\ T.M. Monahon, 703-H \\ C.A. Polson, 707-H \\ V.G. Dickert, 703-H \\ RA. Scaggs, 703-H \\ S.S. Cathey, 719-4A \\ N.R. Davis, 719-4A \\ J.E. Marra, 703-H \\ R.L. Salizzoni, 707-H \\ A.W. Wiggins, 241-168H \\ M.A. Ceravolo, 707-H \\ M.C. Chandler, 703-H \\ D.F. Brown, 703-H \\ G.K. Georgeton, 703-H \\ P.W. Norris, 707-H \\ T.E. Pate, 742-13G \\ G.H. Clare, 704-C \\ S.W. O'Rear, 244-2H \\ R. Martini, 707-C \\ J.S. Baker, 244-2H \\ J.G. McKibbin, 704-2H \\ D.R. Johnson, 704-2H \\ E.R. Selden, 221-14H \\ H.A. McGovern, 221-H \\ G.J. Zachmann, 221-H \\ D.R. Wray, 211-19H \\ T.L. Wood, 211-19H \\ HLWE Files, 703-H
}

